\title{
地雷探知のための低接地圧車両に関する研究* （低接地圧タイヤ特性を考慮した車両位置・姿勢制御方法の提案）
}

\author{
福田 敏 男*1, 佐 藤 慎 祐*2, 長谷川 泰久*3 \\ 松野隆幸*4, Zakarya ZYADA*5
}

\section{Low-Ground-Pressure Vehicle for Landmine Detection \\ (Characteristic of Low-Ground-Pressure Tire and Proposal of Position and Posture Control Technique)}

Toshio FUKUDA*6, Shinsuke SATO, Yasuhisa HASEGAWA, Takayuki MATSUNO and Zakarya ZYADA

\footnotetext{
${ }^{* 6}$ Micro-Nano System Engineering, Nagoya University,
}

1 Furo-cho, Chikusa-ku, Nagoya-shi, Aichi, 464-8603 Japan

\begin{abstract}
This paper proposes a kinematic model of the vehicle with low-ground-pressure tire that enables to enter a minefield in order to scan remaining landmines by a ground penetrating radar in level III survey. The low-ground-pressure tire makes low-pressure contact with a ground by deforming its shape of the tire, but the deformation deteriorates position and steering control accuracy. Therefore this paper models the kinematics of the low-ground-pressure vehicle based on experimental results. Besides we experimentally confirmed that the vehicle could precisely trace the target trajectory by considering its kinematics in simulated minefield.
\end{abstract}

Key Words : Moving Robot, Positioning, Motion Control, Landmine Detection, Vehicle

\section{1. 緒 言}

現在，世界には 5000 万個から 1 億個の埋設地雷が 未処理で放置されているといわれており，重大な社会 問題になっている．現時点では探針や金属探知機を用 いた人の手による除去が一般的である.しかし，その 除去作業によって作業者自身が被害にあうことも少な くない，そこで人に代わるものとしてロボットによる 地雷除去への期待が高まっている，我々は地雷の探知 作業に絞り，ロボットによる地雷探知のための技術を 開発してきた ${ }^{(1)}$ (2).

これまで数々の地雷探査ロボットが研究されてきた が，その多くは地雷を回避しながら地雷原を移動する ものであった ${ }^{(3)}$ (4). そのためには複雑な機構システム や多額のコストが必要になる。しかし，実際の現地で 必要とされるシステムは，現地の人でも使用でき，さ らに修理することも出来る簡単なシステムであり，ま た多額のコストをかけることも出来ない，そこで，我々 は地雷原に直接侵入し，たとえ地雷の上をタイヤが通 過しても地雷を起爆させることなく地雷探知作業を行

\footnotetext{
* 原稿受付 2007 年 7 月 6 日。

*1 正員, フェロー, 名古屋大学大学院工学研究科マイクロ・十 ノシステム工学専攻 (恶 464-8603 名古屋市千種区不老町 1).

*2 名古屋大学大学院工学研究科機械理工学専攻.

*3 正員, 筑波大学大学院システム情報工学研究科 (丞 305-8573 つくば市天王台 1-1-1).

*4 正員, 富山䀠立大学工学部知能デザイン工学科

*5 名古屋大学大学院工学研究科マイクロ・ナノシステム工学 專攻.

E-mail : fukuda@mein.nagoya-u.ac.jp
}

うことができる低接地圧タイヤを用いた車両を提案し てきた (2).この車両は市販のレジャ一用カートを改造 して製作しており，安価で車輪型なので機構システム も複雑ではない. しかし, 実際に車両を制御する際に タイヤが大きく変形するために, 横滑りが大きくなり, その点を考慮した制御をする必要がある。そこで，本 論文ではこれまでに提案してきた低接地圧タイヤを用 いた地雷探査車両の制御方法を提案するとともに，低 接地圧タイヤによる接地圧の低減の効果についても検 証する.

\section{2. 地雷探知システム}

$2 \cdot 1$ システム構成初めに, 低接地圧地雷探査 車両を用いた地雷探知システムについて説明する。車 両は地雷原内で作業を行うが，地雷原から離れた安全 な場所に車両のモニタリングおよび操作を行う固定局 を設置し，作業者はこの固定局から操作する（図 1）。 固定局には自動追尾トータルステーション(反射プリ ズムを自動追尾しながらプリズムと本体との間の相対 座標を計測する機器) を設置し，車両に装備した反射 プリズムとの相対座標を計測する. 固定局側の PC と 車両に搭載したノートPC は無線 LAN によって通信 を行い，固定局側の PCから一定周期で相対座標を車 両に送信する（図 2）。 


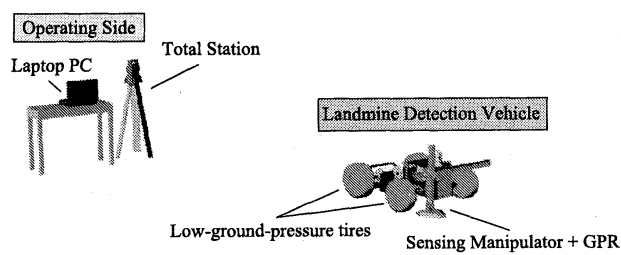

Fig. 1 System appearance

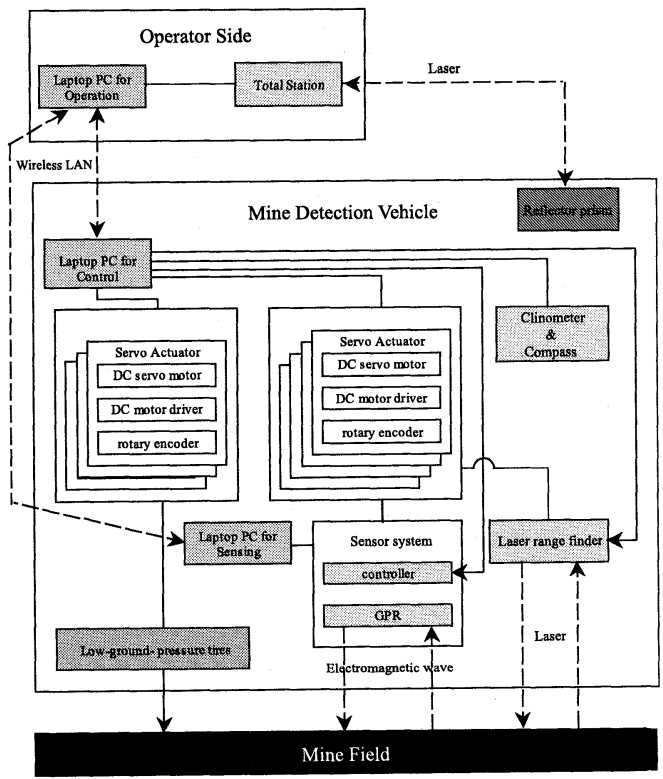

Fig. 2 Detecting system

2.2 低接地圧地雷探査車両図 3 に示寸地雷探 査車両は市販のレジャー用カートのフレームを用い製 作した。このシステム構成は，図 2 に示すように，車 両には, 自立走行を行うための制御器, 通信機器及び バッテリーが搭載され，また，地雷探知センサとして 地中レーダ (Ground Penetrating Radar : GPR) を搭載し ている．我々が使用した地中レーダは，3つのアンテ ナエレメントを有し， 1 計測点で 3 つの送受信偏波角 での計測を行う。これにより，取得された計測信号に 散乱行列処理を加えることで，任意の送受信偏波角で の計測信号を求めることが可能となる ${ }^{(1)(5)}$.ここ地中 レーダのセンサヘッドを，車両前部に取り付けた 4 軸 (縦軸, 横軸, 回転 2 軸) マニピュレータによって地表 面に倣うように走查し, 一定間隔ごとに計測を行う. また車両の姿勢を計測する方位・傾斜計を搭載し，車 両およびマニピュレータの制御用と地中レーダ信号処

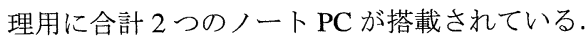

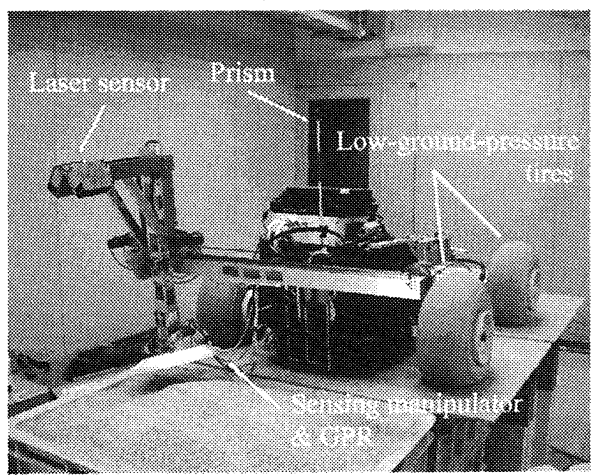

Fig. 3 Overview of low-ground-pressure vehicle

\section{3. 低接地圧タイヤ}

地雷原に直接侵入して地雷探査を行うには，低接地 圧タイヤを使うことでたとえ地雷を踏んでも地雷を起 爆させないことが重要である。本章では実際に低接地 圧タイヤによる接地圧低減の効果を検証する，低接地 圧タイヤとして Roleez Wheels, Inc. 製の低接地圧タイ ヤを使用し; その材質はポリウレンタン製のため内部 の空気圧を調節することで柔軟に地面との接触面積を 大きくし，接触圧力を低減することが可能である.

今回, 地雷として一般的な PMN2, TYPE72, PMN の 3 種類を想定し, それらの起爆平均面圧を表 1 に示 す. PMN の起爆圧 $0.064 \mathrm{kgf} / \mathrm{cm}^{2}$ が条件としては最も 低い圧力で起爆し, すべてのタイヤにこの值を下回る 接地圧が要求される.

Table 1 Ignition pressure

\begin{tabular}{|l||l|l|l|}
\hline & PMN2 & TYPE72 & PMN \\
\hline $\begin{array}{l}\text { Ignition pressure } \\
{\left[\mathrm{kgf} / \mathrm{cm}^{2}\right]}\end{array}$ & 0.26 & 0.19 & 0.064 \\
\hline
\end{tabular}

低接地圧タイヤの効果を検証するために，Fröhlich の公式を用いた地盤内応力の解析および圧力センサを 用いた実験を行う. Fröhlichの公式を使うにあたって 次の条件を仮定する. (1) 地面を半無限弾性板とする. （2）荷重は棈円形状の等分布荷重とする．タイヤ荷重 による地盤内応力を図 4 に示すように定義する.この とき，接地面である棈円の中心を通過する垂直応力は Fröhlichの公式を用いて式 (1)で表される.

$$
\begin{aligned}
\sigma_{z s}= & \frac{\lambda q z^{\lambda}}{2 \pi} \iint_{D}\left(x^{2}+y^{2}+z^{2}\right)^{-\frac{\lambda}{2}-1} d S \\
= & \frac{\lambda q z^{\lambda} a b}{2 \pi} \int_{0}^{2 \pi} \int_{0}^{1} r\left(r ^ { 2 } \left(a^{2} \sin ^{2} \theta\right.\right. \\
& \left.\left.+b^{2} \cos ^{2} \theta\right)+z^{2}\right)^{-\frac{\lambda}{2}-1} d r d \theta
\end{aligned}
$$




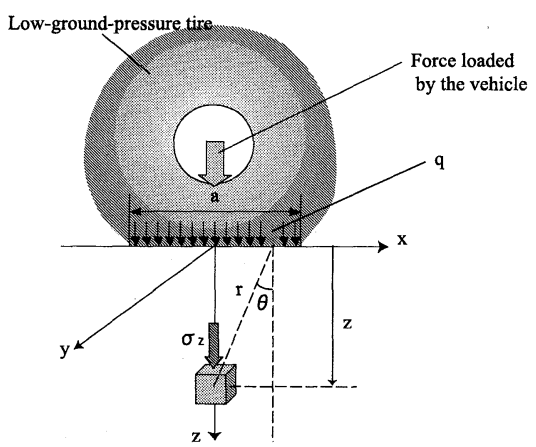

Fig. 4 Subsurface stress by low-ground-pressure tire

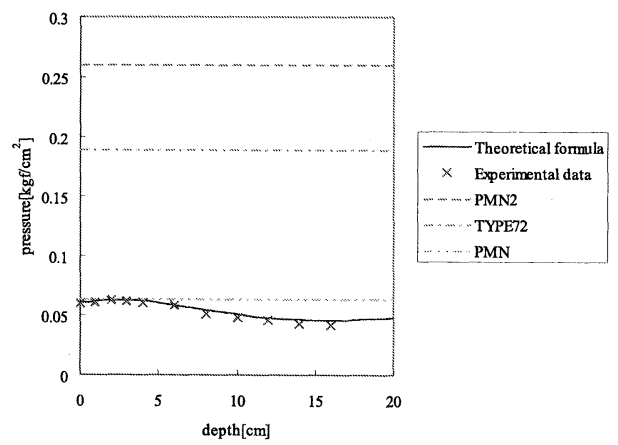

Fig. 5 Subsurface pressure (inner pressure: $80 \mathrm{hPa}$, weight:24.75kg)

ここで, $q$ は地表面での圧力, $a$ は楕円形状の接地面 の長軸, $b$ は短軸, $\lambda$ は応力集中係数を表す.さらに 地中の物体には地中の媒質となる砂や土の自重も応力 として付加される. 地中媒質の自重をその単位体積重 量 $\gamma_{t}$ に比例すると仮定すると次式によって自重による 地盤内応力が求められる.

$$
\sigma_{z_{w}}=\gamma_{t} z
$$

式 (1) と式 (2) を加えた次式によって地盤内の応力を 求めることが出来る. 実際の地雷探知車両の条件を入 れて求めた地盤内応力を図 5 中の実線で示す.

$$
\sigma_{z}=\sigma_{z_{s}}+\sigma_{z_{w}}
$$

地雷探知車両の重量は $88.0 \mathrm{~kg}$ で前方左右輪には $24.75 \mathrm{~kg}$ ずつ, 後方左右輪には $19.25 \mathrm{~kg}$ ずつ荷重がか かっている，そこで荷重の大きい前輪について平坦な 場所で計測した結果を図 6 に示す.この図よりタイヤ の空気圧は下げると接地面が増加するが，空気圧を下

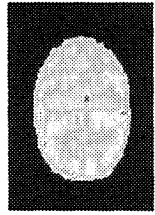

$\mathrm{p}=100 \mathrm{hPa}$

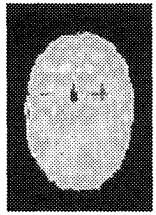

$\mathrm{p}=80 \mathrm{hPa}$

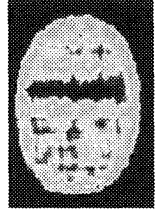

$\mathrm{p}=50 \mathrm{hPa}$ (p: inner pressure of tire)
Fig. 6 Contact area when weight is $24.75 \mathrm{~kg}$

げ過ぎると接触棈円の円周上に荷重が集中し, 最大荷 重が増加してしまうが, 空気圧が約 $80 \mathrm{hPa}$ のときが 荷重分布もほぼ均等分布し最適であることがわかる. そこで, タイヤの空気圧は $80 \mathrm{hPa}$ とし, 圧力センサの 埋設深度を地表面である $0 \mathrm{~cm}$ から地下 $16 \mathrm{~cm}$ までの 場合に分けて測定を行う。その実験による測定結果お よび対象としてる対人地雷の起爆圧を図 5 に追記す る. ほぼ理論值に近い実験結果が得られ, 最大圧力が $0.062 \mathrm{kgf} / \mathrm{cm}^{2}$ となり, 起爆圧である $0.064 \mathrm{kgf} / \mathrm{cm}^{2}$ と同 程度であることが分かった. 今後, 車輪の大型化, 車 両の小型・軽量化を図ることで, 容易に安全マージン を得ることが可能となる.

\section{4. 低接地圧車両の力学モデル}

トータルステーションおよび方位・傾斜計によって車 両の位置と姿勢を計測することが可能であるが，トー タルステーションから車両のノート PCに位置情報を 転送するのに 1.0 ～1.5 秒程度の時間遅れが生じる. そ こで正確な車両の力学モデルを用いてリアルタイムで 車両の正確な位置を推定する．本章では低接地圧車両 の力学モデルを構築する.

低接地圧タイヤでは，タイヤ内部の空気圧が低くタ イヤ自身の剛性が低くなり，旋回時にタイヤの横方向 の変形量が大きい. そこで, 低接地圧タイヤの力学モ デルを求める. 図 7 に示すようにタイヤを 3 方向のば ねで近似したモデルとして扱う ${ }^{(6)}$. 図 8 には接地面の 横方向の変形を示す. 変形したタイヤの接地面は (1) 粘着域:接地面の方向が滑り角方向にほぼ一致する領 域と，(2)すべり域:接地面の方向が滑り角方向は追従 せず，地面に対してタイヤがすべりを生じる領域の 2 つの領域に分けられる. また，粘着域では横方向の応 力がタイヤの横方向の剛性と弾性変形によって支配さ れ，すべり域では横方向の応力が接地圧とタイヤと地 面との間の摩擦係数によって支配されることがわかっ ている ${ }^{(6)}$. 図 9 に示すように, 粘着域での横方向の変 化は接地面の縦方向を $\xi$ 軸, 横方向を $\eta$ 軸としたと き，すべり角 $\alpha$ を用いて次式で表される. 


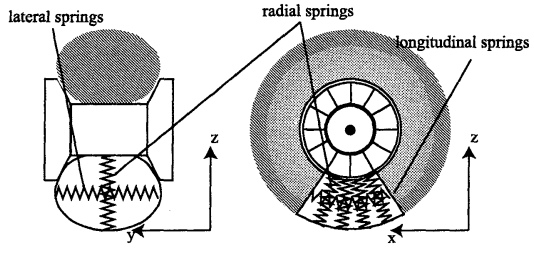

Fig. 7 Tire model of three directional springs

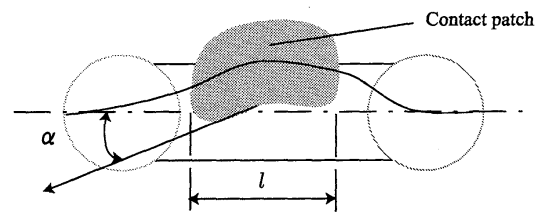

Fig. 8 Contact patch of tire

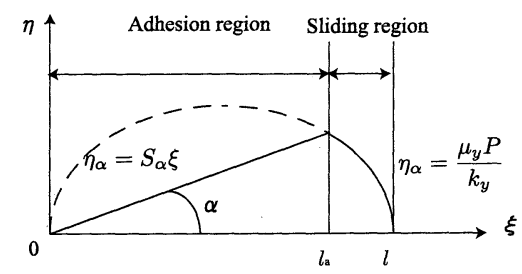

Fig. 9 Lateral deformation

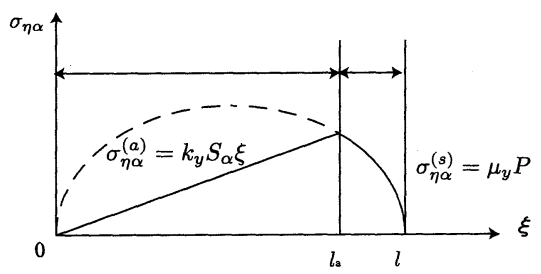

Fig. 10 Lateral stress

$$
\Delta \eta_{\alpha}=|\tan \alpha| \Delta \xi=S_{\alpha} \Delta \xi
$$

よって, 横方向の応力は

$$
\sigma_{\eta \alpha}^{(a)}=k_{y} \Delta \eta_{\alpha} \quad\left(0 \leq \xi \leq l_{a}\right)
$$

と求められる.ここで $k_{y}$ は横方向の弾性係数, $l_{a}$ は 粘着域とすべり域の境界までの長さを表している（図 10 参照).

次に，すべり域での忘力を求める. 前述のとおりす ベり域では横方向の応力が接地圧とタイヤと地面との 間の摩擦係数によって支配されることから，

$$
\sigma_{\eta \alpha}^{(s)}=\mu_{y} P \quad\left(l_{a} \leq \xi \leq l\right)
$$

となる.ここで $\mu_{y}$ はタイヤと地面との間の摩擦係数, $P$ は垂直応力を表している. 以上から全体の横方向の 力は次のように求められる.

$$
\begin{aligned}
F_{\eta \alpha} & =\int_{0}^{l} \sigma_{\eta \alpha} w d \xi \\
& =\int_{0}^{l_{a}} \sigma_{\eta \alpha}^{(a)} w d \xi+\int_{l_{a}}^{l} \sigma_{\eta \alpha}^{(s)} w d \xi
\end{aligned}
$$

実際には，この横方向の力を圧力センサシートを用 いて求める. 圧力センサシートを使うことでタイヤ接 地面の接地圧分布と接地面形状を計測することができ る. その計測データをもとに, 式 (7) から横方向の力 を計算することが出来る，そして，す心゙り角と横方向 の力が一対一の関係にあると仮定することで，実際の 制御中でも各タイヤのすべり角が分かれば，事前に圧 カセンサシートで計測したデータを用いて横方向の力 を導出することが出来る.

次に, 車両の力学モデルとして図 11 に示す 4 輪モ デルを用い, 車両の力学モデルを導出する.

実際の地形には多少の凹凹はあるが簡略化のため平 坦とみなすと, 車両の運動方程式は次式で表される.

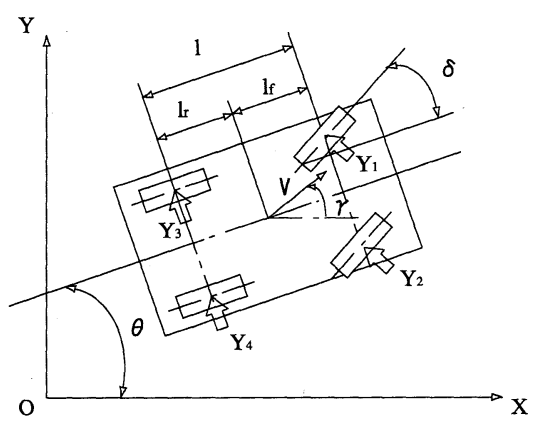

Fig. 11 Vehicle kinematic model

$$
\left\{\begin{aligned}
m \frac{d^{2} x}{d t^{2}}= & \sum_{i=1}^{4} Y_{x i}+\sum_{i=1}^{4} N_{x i}+\sum_{i=3}^{4} F_{x i} \\
m \frac{d^{2} y}{d t^{2}}= & \sum_{i=1}^{4} Y_{y i}+\sum_{i=1}^{4} N_{y i}+\sum_{i=3}^{4} F_{y i} \\
I \frac{d^{2} \theta}{d t^{2}}= & \sum_{i=1}^{2} Y_{i} \cos \left(\alpha_{i}+\delta\right) l_{f}+\sum_{i=3}^{4} Y_{i} \cos \left(\alpha_{i}\right) l_{r} \\
& \quad+\sum_{i=1}^{2} N_{i} \sin \left(\alpha_{i}+\delta\right) l_{f}+\sum_{i=3}^{4} N_{i} \sin \left(\alpha_{i}\right) l_{r}
\end{aligned}\right.
$$

ただし， $m$ : 車両の質量， $N$ : 地面とタイヤの転がり 抵抗, $F$ : 駆動力, $I$ : 重心周りの慣性モーメント, $\delta$ : ステアリング角, $l_{f}$ : 車体重心と前輪軸の距離, $l_{r}$ : 車体重心と後輪軸の距離である. また, このとき各夕 イヤのす心゙り角 $\alpha_{i}$ は車両のすべり角 $\alpha$ を用いて次式 にて推定される. 


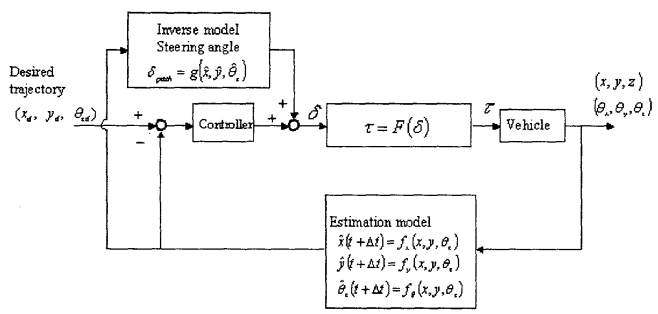

Fig. 12 Blockdiagram

$$
\left\{\begin{array}{l}
\alpha_{1}=\frac{V \sin \alpha+l_{f} \frac{d \theta}{d t}}{V \cos \alpha-\frac{d}{2} \frac{d \theta}{d t}}-\delta \\
\alpha_{2}=\frac{V \sin \alpha+l_{f} \frac{d \theta}{d t}}{V \cos \alpha+\frac{d}{2} \frac{d \theta}{d t}}-\delta \\
\alpha_{3}=\frac{V \sin \alpha-l_{r} \frac{d \theta}{d t}}{V \cos \alpha-\frac{d}{2} \frac{d \theta}{d t}} \\
\alpha_{4}=\frac{V \sin \alpha-l_{r} \frac{d \theta}{d t}}{V \cos \alpha+\frac{d}{2} \frac{d \theta}{d t}}
\end{array}\right.
$$

\section{5. 軌道追従制御}

$5 \cdot 1$ 制御手法 図 12 に提案した車両モデルを用 いた軌道追従制御のための制御系を示す，速度は一定 とし，ステアリング角 $\delta$ のみ制御入力として用いる. 出力は一定時間ごとにトータルステーションによって 計測される車両の位置 $(x, y, z)$ と逐次計測される車両の 姿勢角 $\left(\theta_{x}, \theta_{y}, \theta_{z}\right)$ になる. 今回は平坦地形を仮定して いるので実際に必要となるのは現時点での $x, y, \theta_{z}$ にな る. $\theta_{z}$ は逐次計測されるのでそのままの值を用い, 一 定時間ごとにしか更新されない位置 $(x, y)$ については これまでに提案した車両モデルを用いて推定する．図 13 に示すように一定時間ごとに更新される状態を初期 状態として現在までの経過時間から現在の状態を推定 する. その推定值 $(\hat{x}, \hat{y})$ と実測值 $\theta_{z}$ をフィードバック 值として用いる．フィードバック值と目標軌道との誤 差にゲインを掛けた值に目標軌道に追従するための值 を付加した值が実際に入力するステアリング角になる.

5.2 実験条件実験フィールドはほぼ平坦な場 所であり, 地表面は砂で覆われている，実際の地雷原 は凹凹があり，必ずしも平坦であるとは言えない，し かし, 本車両は重機で一度地雷原を平坦にならした後

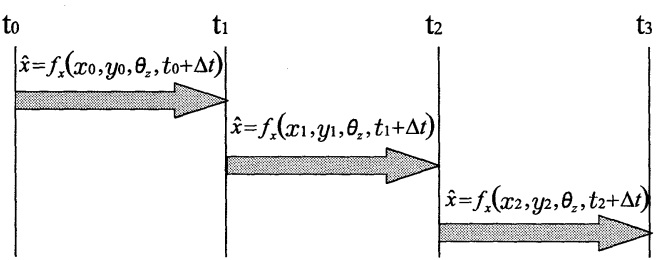

Fig. 13 Timing of position estimation and of data acquisition

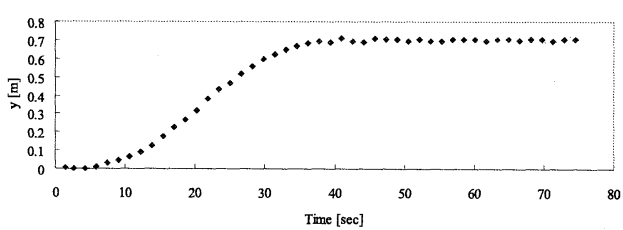

Fig. 14 Vehicle trajectory in y direction

（レベル 2 サーベイ後）に使うことを前提としている ため, 平坦地で実験を行った. 目標となる軌道は $\mathrm{y}=0$ のレーンから $\mathrm{y}=0.7 \mathrm{~m}$ のレーンへの車線変更を行う軌

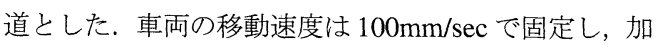
減速や旋回時も準静的として扱える速度である.

$5 \cdot 3$ 実験結果 図 14 に方向の車両の軌跡の時 系列データを示す．車両の軌跡は滑らかで $\mathrm{y}=0.7 \mathrm{~m}$ の レーンにスムーズに移動できていることが分かる．図 15 (a)に目標の軌道と実際に車両の通過した軌跡を， 図 16 に目標軌道との位置誤差を, 図 17 に姿勢角誤差 を示す.ここで $\Delta d=\sqrt{\Delta x^{2}+\Delta y^{2}}$. 車両は目標軌道を 正確に追従していることが分かる. 位置の目標軌道と の誤差は $\pm 0.015[\mathrm{~m}]$ 以内に，姿勢角の誤差は $\pm 5[\mathrm{deg}]$ 以内に収まっている. 図 15 (b) はコーナリングフォー スを近似した通常モデルを用いた場合の軌道追従実験 の結果を示している．コーナリングフォースを近似し たモデルを用いたときは，レーンの移動をする際の旋 回動作時に軌道から大きく外れ追従していない.この ことからコーナリングフォースを近似したモデルでは 低接地圧車両の実際の挙動を現すことができていない と言える.

\section{6. 斜面での軌道追従制御精度}

斜面では, 車両座標系から重力方向が異なり, 各車 輪への荷重も変化する.そこで, 平地での実験と同じ 条件（車両の移動速度は $100 \mathrm{~mm} / \mathrm{sec}, \mathrm{y}=0$ のレーンか ら $\mathrm{y}=0.7 \mathrm{~m}$ のレーンへの車線変更）にて, 平均斜度 8.2 ○のコンクリートの傾斜地での軌道追従性を確認する. 


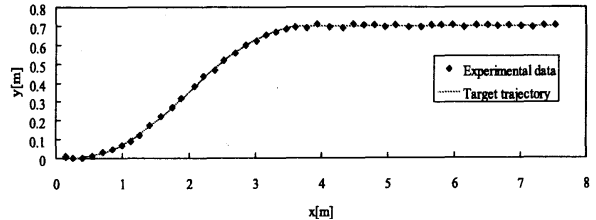

(a) Proposed model

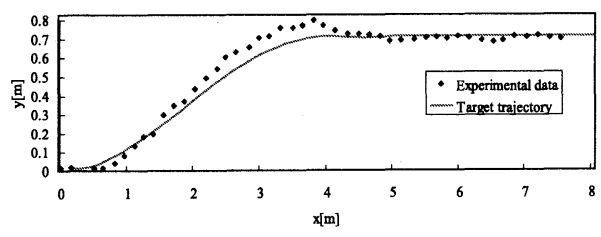

(b) Conventional linearization model

Fig. 15 Path of the vehicle

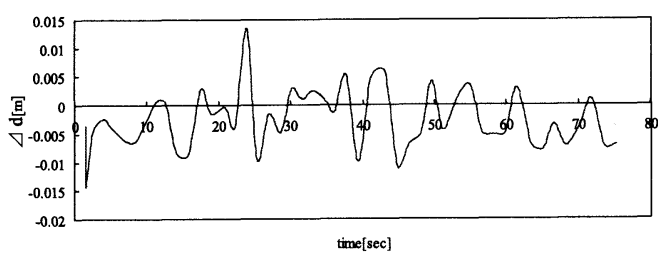

Fig. 16 Position error

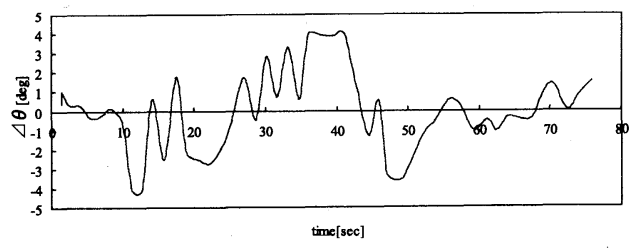

Fig. 17 Posture error

その実験結果を図 18, 図 19 に示す. 図 18 には実 際にトータルステーションによって計測された位置を 示している. 図 19 にはそのトータルステーションの 位置データと方位・傾斜計の姿勢データをもとに車両 の予測モデルによってリアルタイムに計算した車両の 位置を示している. 距離誤差 $d$ は, $0.030 \mathrm{~m}$ 以内と比 較的良い追従性を保っている. $\mathrm{X}=2.5 \mathrm{~m}$ 付近で誤差が $0.068 \mathrm{~m}$ と一度大きくなっているが, これは, プリズ ムの振動による外乱の影響と推定され, タイヤの静的 な変形による誤差ではないと考えられる. それは, 図 18 を見ると目標軌道から大きく外れたことを示す計 測点は 1 点しかなく, その直後の計測点以降は, 目標 軌道にほぼ戻っており，すべての計測点が正しいとす ると車両が高速に $\mathrm{y}$ 方向に移動したことになる.しか

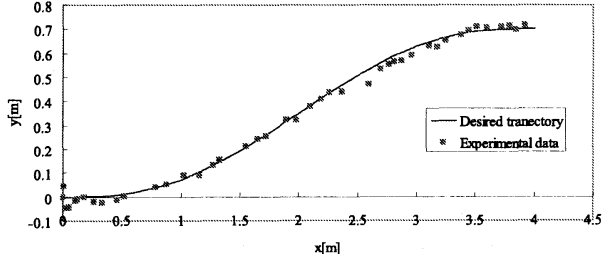

Fig. 18 Vehicle position measured by total station

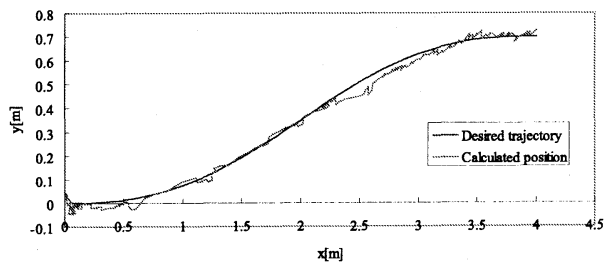

Fig. 19 Interpolated vehicle position using the proposed vehicle kinematics

し，これほど速く車両が操舵により移動することは物 理的に不可能であるため，1点の大きく外れた計測点 に誤差が含まれていると考えられる.

\section{7. 結言}

本論文では，埋設された対人地雷を起爆しない程度 に地表面との接地圧力を低くすることが可能な低接地 圧タイヤを用いた地雷探知車両およびその位置制御手 法を提案した。 まず，低接地圧タイヤが対人地雷の起 爆圧を下回る接地圧力が実現可能であることを確認し た後, 変形量の大きい低接地圧タイヤに搭載した車両 の位置制御精度向上を目的とし，車両のすべり角から 各タイヤのすべり角および作用力を求め, 車両の力学 モデルから得られた推定位置からステアリング角を決 定するアルゴリズムを提案した．また，平地および斜 面での軌道追従実験を行い，十分な精度が得られるこ とを確認した.

今後の課題として，地雷を起爆させない接地圧の安 全率の向上および，実際の地雷原での作業を想定した インタフェースの整備を行う必要がある.

\section{文献}

(1) Fukuda T., Yokoe K., Hasegawa Y., and Fukui T., Land mine detection algorithm using Ultra Wide Band GPR, Proceedings of the first International Symposium on Systems and Human Science for Safe, Secure, and Reliable Society: SSR, (2003), pp.295-300. 
(2) Fukuda T., Hasegawa Y., Kosuge K., Komoriya K., Kitagawa F., and Ikegami T., Environment-AdaptiveAntipersonnel Mine Detection System, Journal of the Society of Instrument and Control Engineers, Vol.45, No.6, (2006), pp.518-524.

(3) Nonami K., Development of mine detection robot cometii and comet-iii, Proceedings of the 41st SICE Annual Conference (SICE 2002), Vol. 1, (2002), pp.5-7.

(4) Kato K., and Hirose S., Development of the quadruped walking robot, titan-ix - mechanical design concept and application for humanitarian demining robot, Advanced Robotics, Vol.15, (2001), pp. 191-204.

(5) Yabushita, H., Kanehama M, Hirata Y., Kosuge K., 3D Ground Adaptive Synthetic Aperture Radar for Landmine Detection, Proceedings of the 2005 IEEE/RSJ International Conference on Intelligent Robots and Systems, (2005), pp.1861-1866.

(6) Gwanghun Gim, Parviz E. Nikravesh, An analytical model of pneumatic tyres for vehicle dynamic simulations. Part 1: Pure slips, International Jounal of Vehicle Design, Vol. 11, No. 6, (1990), pp.589-618. 